\title{
Adenosine or Magnesium Sulphate as Adjuvants for Pectoral Nerves Block in Modified Radical Mastectomy: A Randomized Controlled Trial
}

\author{
Ezzeldin Saleh Ibrahim*, Wesameldin Abdelrahman Sultan \\ Department of Anaesthesia and Intensive Care, Faculty of Medicine, Menoufia University, Shebeen El Kooom, Egypt \\ Email: *ezzeldin7@yahoo.com
}

How to cite this paper: Ibrahim, E.S. and Sultan, W.A. (2018) Adjuvants for Pectoral Nerves Block in Modified Radical Mastectomy: A Randomized Controlled Trial. Open Journal of Anesthesiology, 8, 159-171. https://doi.org/10.4236/ojanes.2018.85017

Received: May 5, 2018

Accepted: May 28, 2018

Published: May 31, 2018

Copyright $\odot 2018$ by authors and Scientific Research Publishing Inc. This work is licensed under the Creative Commons Attribution International License (CC BY 4.0).

http://creativecommons.org/licenses/by/4.0/

\begin{abstract}
Introduction: Magnesium sulphate can prolong the effect of local anaesthetics. Adenosine has not been compared to other local anaesthetics adjuvants. In the present study we aimed to compare the effect of adding magnesium sulphate and adenosine to bupivacaine for pectoral nerves block. Patients and Methods: In this randomized controlled trial, 90 females scheduled for breast surgery were included. Patients were divided into three groups. Patients received general anaesthesia with pectoral nerves block. Group C, A, and M had bupivacaine only, bupivacaine + adenosine, and bupivaciane + magnesium sulphate respectively. Post-operative visual analogue score, block duration, post-operative morphine consumption, sedation score, and peri-operative haemodynamic changes were recorded. Results: Visual analog score was lower in Group M compared to other groups. Group A and M showed significant longer duration of the block. Group $M$ showed significant longer duration of action than Group A $(p=0.034)$. The total peri-operative morphine used was higher in Group C $(p<0.05)$. Post-operative Ramsay sedation score was significantly lower in Group A during the first two hours post-operatively $(p>$ $0.05)$. Conclusions: Local anaesthetic adjuvants such as adenosine or magnesium sulphate can improve pectoral nerves block characteristics. Magnesium sulphate has an advantage over adenosine by increasing the block duration.
\end{abstract}

\section{Keywords}

PECS Block, Adenosine, Magnesium Sulphate

\section{Introduction}

Breast surgery has increased recently due to the increased incidence of breast 
cancer among females [1] [2]. Badly managed acute post-operative pain may lead to chronic persistent pain with poor quality of recovery [3] [4]. Post-operative pain for breast surgery can be controlled by pain regular medications such as paracetamol, non-steroidal anti-inflammatory (NSAIDs), and narcotics [5] [6] [7] [8]. Nerve blocks are commonly used as multimodal approaches for acute post-operative pain relief [5].

Thoracic paravertebral block is another module for post-operative pain control in breast surgery. This invasive technique has its complications that made it unpopular for this superficial surgery [9]. Pectoral nerves block (PECS) are less invasive novel technique described by Blanco et al. for post-operative pain control in this group of patients [10].

It has been shown that adjuvants to local anaesthetics can prolong its action. Magnesium sulfate has been shown to prolong the effect of local anaesthetics when used as an adjuvant in local injections or in nerve blocks techniques [11] [12]. It has been shown that adenosine plays a role in nerves regeneration and it has an effect on peripheral and central nerves mediators to provide analgesia [13] [14] [15].

We hypothesized that adding local anaesthetic adjuvants such as adenosine or magnesium sulphate in PECS I and II blocks can improve the block quality. In the present study we aimed to compare the effect of magnesium sulfate and adenosine as adjuvants to the local anaesthetic in PECS blocks for post-operative pain relief in patients undergoing breast surgery. Our primary goal was to compare the block quality, and its analgesic effect in reducing post-operative opioid consumption.

\section{Material and Methods}

After approval from the ethics committee of Menoufia University Hospital and informed written consent from the patients, the present study was conducted on 90 adult females aged between 20 and 65 years old. Patients scheduled for modified radical mastectomy with axillary clearance surgery ASA classes II, and III were included in the study. Inclusion criteria included; 1) patients who agreed to take part in the study, 2) patients with not known allergic to any of the medications used in the study, and 3) female patients diagnosed with cancer breast. Exclusion criteria included; 1) contraindications for regional anaesthesia such as coagulopathy, local infection and fungating breast cancer, 2) history of allergy to any of the medications used in the study, 3) patient with history of drug abuse, 4) previous breast surgery except for diagnostic biopsies, 5) history of treatment for a chronic pain conditions, 6) psychiatric disorder, and 7) patients with post-radiotherapy fibrosis at the site of the block. Pre-operatively patients were taught how to express the severity of their pain by using the Visual Analog Scale (VAS) where $0=$ no pain and $10=$ worst pain [16].

Patients were randomly allocated into one of three groups according to the local anaesthetic adjuvant, 30 patients in each group using a computerized program. 
All patients received PECS I and II blocks followed by general anaesthesia after assessment of the block. Group C received PECS with 0.25\% bupivacaine (control group), Group A bupivacaine with added adenosine, and Group M bupivacaine with added magnesium sulfate.

All patients had an intravenous line in the contra lateral arm of the surgical side and were attached to the standard monitoring. Patients received 2 - $3 \mathrm{mg}$ midazolam as a sedative before PECS was performed.

\subsection{Technique for PECS Block}

Infra-clavicular and axillary regions were disinfected using chlorhexidine-alcohol or povidone iodine if the patient was allergic to chlorhexidine-alcohol. The ultrasound probe was used aseptically. The ultrasound machine Sonosite M-Turbo, Bothell, Washington, USA with a high frequency linear (6 - $13 \mathrm{MHz}$ ) probe was used for the block. The probe was placed obliquely under the lateral third of the clavicle. After identification of the axillary artery the probe was moved distally towards the axilla to locate the 2nd, 3rd and 4th ribs, at this level the lateral border of the pectoralis major and pectoralis minor muscles were identified. The plane between the pectoralis major and pectoralis minor muscles was targeted for the block. After identification of the site of entry, the skin puncture point was infiltrated with $0.2 \mathrm{ml}$ of $2 \%$ lignocaine by 27 guage insulin needle. In plane technique was used for the block with a 22-gauge hyperechoic needle from the medial to lateral side. $10 \mathrm{ml}$ from the prepared solution was injected at the level of 4 th rib (PECS I) then the needle was advanced deeply to reach the plane between the pectoralis minor and serratus anterior muscles and $20 \mathrm{ml}$ from the solution was injected (PECS II). Figure 1 shows the ultrasound anatomical structures for PECS block.

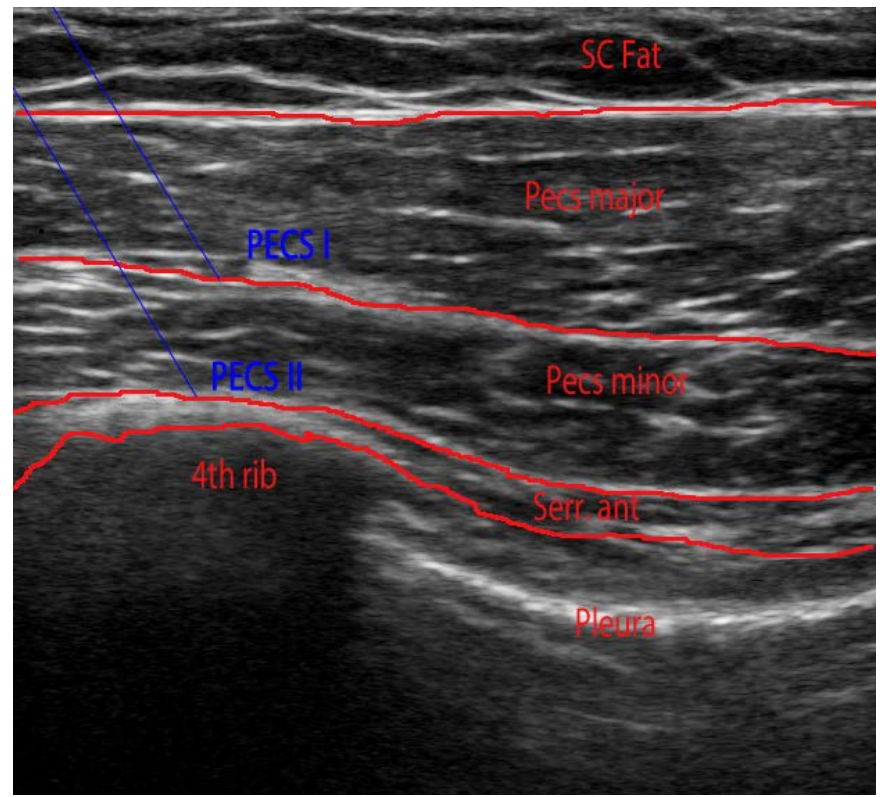

Figure 1. Ultrasound anatomical structures for PECS I and PECS II. 


\subsection{Local Anaesthetics Preparation}

An independent anaesthetist prepared the syringes with the local anaesthetic mixed with the adjuvant according to the study group. The researchers and the patients were blinded to the local anaesthetic adjuvant. All patients received 10 $\mathrm{ml}$ local anaesthetic for PECS I and $20 \mathrm{ml}$ for PECS II. The $30 \mathrm{ml}$ local anaesthetic used for each patient contained bupivacaine hydrochloride $0.25 \%$ only, bupivacaine hydrochloride $0.25 \%$ and $12 \mathrm{mg}$ adenosine [17], and bupivacaine hydrochloride $0.25 \%$ and $500 \mathrm{mg}$ magnesium sulphate [17] for Groups C, A, and $M$ respectively.

We used cold and pinprick tests to confirm the anaesthetic area over T2 - T6 after performing the blocks. All patients received general anaesthesia after confirming the success of the block. General anaesthesia was induced with propofol 2 - $3 \mathrm{mg} \cdot \mathrm{kg}^{-1}$, fentanyl $1 \mathrm{mg} \cdot \mathrm{kg}^{-1}$, and cisatracurium $0.12 \mathrm{mg} \cdot \mathrm{kg}^{-1}$. Anaesthesia was maintained with sevoflurane in $50 \% \mathrm{O}_{2}$ and air. $1-2 \mathrm{mg}$ morphine sulfate was given to maintain blood pressure and heart rate values within $20 \%$ of the baseline. PECS blocks were considered to be insufficient for patients who required intra-operative morphine and were excluded from the analysis. 5 to 10 mg cisatracurium was given if required according to the never stimulator monitoring. Neostigmine and Glycopyrrolate were used to recover the patients. After responding to verbal command with full regain of muscle power patients were extubated and transferred to the post-anesthesia care unit (PACU). Postoperative pain was managed by regular doses of oral paracetamol $1 \mathrm{mg}$ every 8 hours and intravenous ketorolac $30 \mathrm{mg}$ every 8 hours after recovery from the block. Intravenous morphine sulphate $2 \mathrm{mg}$ was given if VAS was $>3$ and be repeated until the VAS was $\leq 3$. Recovery from the block was considered when the first post-operative rescue morphine dose was given. Patients were followed up and data were collected for 24 hours post PACU discharge.

Patients' demographic data were collected including age, BMI, ASA, and duration of surgery. Baseline mean arterial blood pressure and heart rate were recorded before induction and every 15 minutes intra-operatively until the end of the surgery. The total intra-operative morphine consumption was recorded. In PACU the visual analogue score (VAS) was assessed on arrival and then every 15 minutes. VAS was assessed at 1, 2, 3, 6, 12, and 24 hours post-PACU discharge. The duration of the block was calculated from the pre-operatively time when the block was tested and considered to be successful until the first dose of post-operative rescue morphine dose (post-operative VAS of more than 3). The total amount of post-operative morphine used was recorded for all patients. Ramsay sedation score (RSS) was assessed every 15 minutes in PACU and at the same post-operative time of recording VAS. RSS score grades were defined by 1 $=$ anxious and fully awake, 2 = fully awake, 3 = conscious but drowsy, 4 = asleep but reactive to verbal commands, $5=$ asleep but responsive to palpable stimulus, and $6=$ asleep and not responsive to any stimulus [18].

Side effects in PACU were observed such as hypotension, bradycardia, and 
respiratory depression. Hypotension and bradycardia were considered if the mean arterial blood pressure or the heart rate were less than $20 \%$ of the baseline. Respiratory depression was defined if the arterial oxygen saturation $\left(\mathrm{SPO}_{2}\right)<$ $92 \%$ when patients were on $3 \mathrm{~L}$ of oxygen via nasal cannula with.

\subsection{Data Analyses}

The sample size was calculated using GraphPad Instat statistics version 3. Based on previous studies bupivacaine with added magnesium sulphate was expected to reduce postoperative pain score and analgesic requirements by $30 \%$ as a primary outcome. The calculated sample size was 25 patients, with the level of significance being 0.05 and the power being $90 \%$. Thirsty patients were randomized into each group to ensure reliable results.

Statistical analysis was done using SPSS 19 (SPSS Inc, an IBM company, Chicago, USA). Incidence of side effects were analysed using the chi-square $\chi 2$-test. The other parameters were compared using ANOVA test. A $p$ value less than 0.05 was considered to be statistically significant. Kruskal-Waills test is used to analyze data for categorical variables or data that did not obey the normal distribution.

\section{Results}

A total number of 113 consecutive patients were considered to be eligible for the study. 12 of them did not match the inclusion criteria. 101 patients had PECS. However, 11 patients were excluded from the study due to failed block; four is Group C, four in Group A, and three in Group M. 90 patients followed the inclusion criteria and their data were analyzed. Two patients in Group A, two patients in Group M, and three patients in Group $\mathrm{C}$ who required morphine intra-operatively were excluded from the analysis because the block was announced as insufficient block. Figure 2 shows the patients included in the study and the total number of patients their data were included in the analysis. Patients' demographic data were similar in all groups with no statistical differences (Table 1). There was no significant difference regarding the baseline mean arterial blood pressure and heart rate in all groups. Intra-operative and early post-operative mean arterial blood pressure and heart rate were statistically lower in Group A and M compared to Group C $(p<0.05)$. Late post-operative there was no differences regarding the mean atrial blood pressure and heart rate (Figure 3, Figure 4).

VAS was significantly lower in Groups A and M compared to Group C at admission to PCAU and the whole follow up period. VAS was lower in Group $M$ compared to Group A in 06:00 and 12:00 hours post-operatively $(p<0.05)$. The time of first rescue morphine dose post-operatively was significantly longer in Group A and M compared to Group C $(p=0.03)$ and it was significantly longer in Group M when compared to Group A $(p=0.023)$. Group A and M showed statistically significant longer duration of the block compared to Group C. PECS 


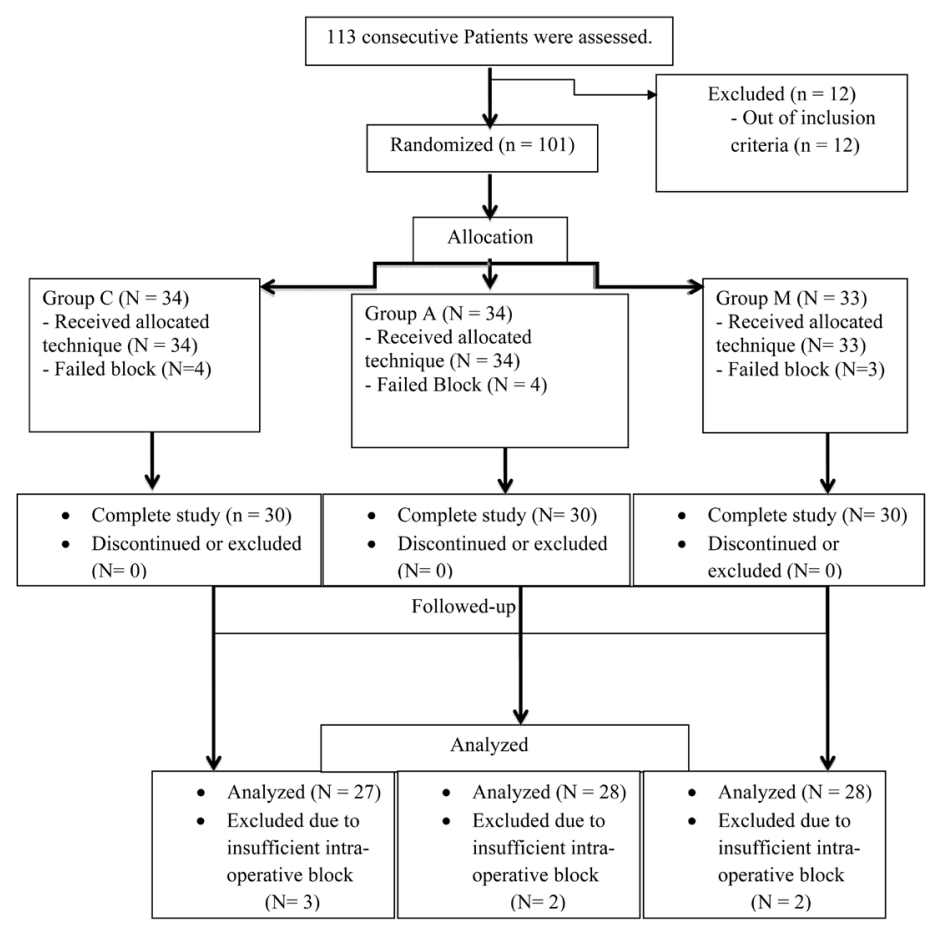

Figure 2. The study groups (the total number of patients recruited, followed up, and analyzed).

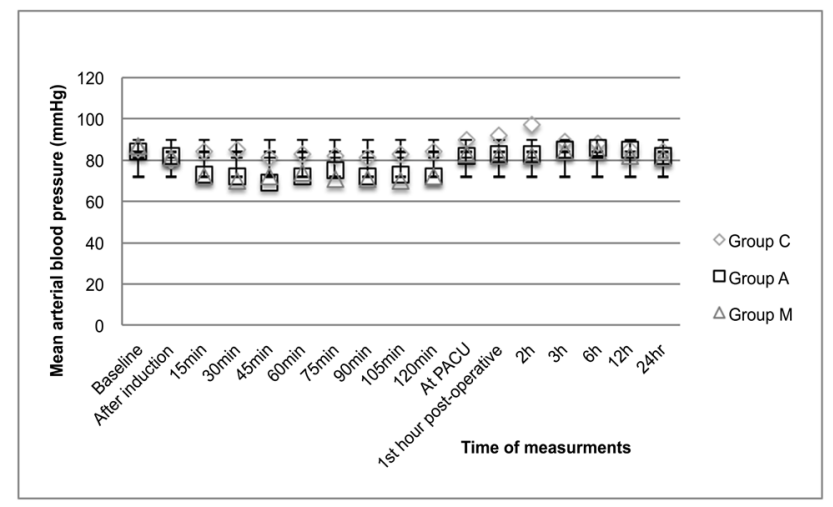

Figure 3. Peri-operative mean arterial blood pressure ( $\mathrm{mmHg})$.

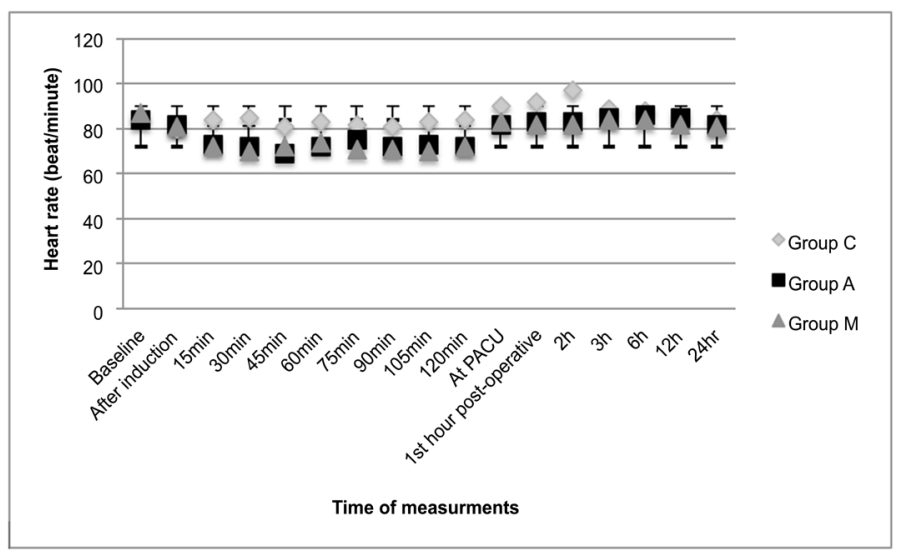

Figure 4. Peri-operative mean heart rate (beats/minutes). 
Table 1. Patients' demographic data.

\begin{tabular}{|c|c|c|c|c|}
\hline Variables & $\begin{array}{c}\text { Group C } \\
N=27\end{array}$ & $\begin{array}{c}\text { Group A } \\
N=28\end{array}$ & $\begin{array}{c}\text { Group } M \\
N=28\end{array}$ & $p$ \\
\hline Age (year) & $51.39 \pm 5$ & $50.63 \pm 6.51$ & $51.24 \pm 5.4$ & 0.35 \\
\hline Height $(\mathrm{cm})$ & $163.18 \pm 4.11$ & $165.51 \pm 6.64$ & $163.65 \pm 4.98$ & 0.29 \\
\hline Weight $(\mathrm{kg})$ & $73.11 \pm 6.72$ & $71.24 \pm 5.28$ & $72: 78 \pm 5.18$ & 0.24 \\
\hline BMI & $27.46 \pm 3.3$ & $26.65 \pm 3.7$ & $26.10 \pm 1.6$ & 0.34 \\
\hline \multicolumn{5}{|l|}{ Sociodemographic } \\
\hline \multicolumn{5}{|l|}{ - Race } \\
\hline White & $22 \%$ & $19 \%$ & $21 \%$ & 0.28 \\
\hline Black & $78 \%$ & $81 \%$ & $79 \%$ & 0.31 \\
\hline \multicolumn{5}{|l|}{ - Marital status } \\
\hline Single & $10 \%$ & $7 \%$ & $9 \%$ & 0.24 \\
\hline Married & $90 \%$ & $93 \%$ & $91 \%$ & 0.29 \\
\hline \multicolumn{5}{|l|}{ - Tobacco use } \\
\hline Smoker & $2 \%$ & $1 \%$ & $1 \%$ & 0.23 \\
\hline Non-smoker & $98 \%$ & $99 \%$ & $99 \%$ & 0.35 \\
\hline \multicolumn{5}{|l|}{ Clinical data } \\
\hline \multicolumn{5}{|l|}{ - Family history } \\
\hline Positive & $20 \%$ & $18 \%$ & $19 \%$ & 0.39 \\
\hline Negative & $80 \%$ & $82 \%$ & $81 \%$ & 0.36 \\
\hline \multicolumn{5}{|l|}{ - Menopausal status } \\
\hline Post-menopausal & $52 \%$ & $57 \%$ & $58 \%$ & 0.43 \\
\hline Premenopausal & $48 \%$ & $43 \%$ & $42 \%$ & 0.31 \\
\hline \multicolumn{5}{|l|}{ - Stage of diagnosis } \\
\hline Early Stage 1 - 2 & $78 \%$ & $76 \%$ & $74 \%$ & 0.28 \\
\hline Late Stage $>2$ & $22 \%$ & $24 \%$ & $26 \%$ & 0.38 \\
\hline $\begin{array}{l}\text { Duration of surgical } \\
\text { procedure (minutes) }\end{array}$ & $109.7 \pm 9.9$ & $113.5 \pm 11.5$ & $112: 5 \pm 12.8$ & 0.31 \\
\hline \multicolumn{5}{|l|}{ ASA Score } \\
\hline I & $6(22.2 \%)$ & $4(14.3 \%)$ & $4(14.3 \%)$ & \\
\hline II & $16(59.3 \%)$ & $19(68 \%)$ & $18(64.3 \%)$ & 0.36 \\
\hline III & $5(18.5 \%)$ & $5(17.7 \%)$ & $6(21.4 \%)$ & \\
\hline
\end{tabular}

Data expressed as mean and standard deviation (Mean $\pm \mathrm{SD}$ ), and percentage (ANOVA test).

in Group $M$ showed significant longer duration of action than Group A ( $p=$ 0.034). There were no statistical differences regarding post-operative complications between the three groups $(p>0.05)$. Table 2 shows the post-operative characteristics for the groups. Post-operative Ramsay sedation score was significantly lower in Group A and M compared to Group C during the first two hours post-operatively $(p>0.05)$. There was no statistical difference regarding Ramsay 
Table 2. Postoperative characteristics.

\begin{tabular}{|c|c|c|c|c|}
\hline Variables & $\begin{array}{l}\text { Group C } \\
(\mathrm{N}=27)\end{array}$ & $\begin{array}{l}\text { Group A } \\
(\mathrm{N}=28)\end{array}$ & $\begin{array}{l}\text { Group } M \\
(\mathrm{~N}=28)\end{array}$ & $p$ \\
\hline \multicolumn{5}{|l|}{ VAS (pain score) } \\
\hline Н 0.00 & $3[3-4]$ & $0[0-0]$ & $0[0-0]$ & $<0.001^{\star *}$ \\
\hline H 1:00 & $3[2-3]$ & $0[0-1]$ & $0[0-2]$ & $<0.001^{\star *}$ \\
\hline H 2:00 & $3[2-3]$ & $1[1-2]$ & $1[1-1]$ & $<0.001^{\star *}$ \\
\hline H 3:00 & $3[2.5-3]$ & $2[1-2]$ & $1[1-2]$ & $<0.001^{\star *}$ \\
\hline H 6:00 & $4[4-4.5]$ & $3[2-3]$ & $2[1-2]$ & $<0.001^{\star \star}$ \\
\hline H 12:00 & $4[4-4.5]$ & $3.5[3-4]$ & $2[1-3]$ & $<0.05^{*}$ \\
\hline H 24:00 & $4[4-5]$ & $3.5[3-4]$ & $3[2-3]$ & $<0.05^{*}$ \\
\hline $\begin{array}{l}\text { Duration of the block (Mean } \pm \text { SD) } \\
\text { (minutes) }\end{array}$ & $345.3 \pm 20.6$ & $453.7 \pm 12.8$ & $573.9 \pm 9.6$ & $\begin{array}{c}0.02^{\star} \\
p_{2}=0.017^{\star}\end{array}$ \\
\hline $\begin{array}{l}\text { Total post-operative morphine used } \\
\qquad(\text { Mean } \pm \text { SD) }(\mathrm{mg})\end{array}$ & $17 \pm 2.5$ & $8 \pm 2.5$ & $6 \pm 1.5$ & $\begin{array}{c}<0.05^{*} \\
p_{2}=0.52\end{array}$ \\
\hline \multicolumn{5}{|l|}{ Post-operative complications } \\
\hline Hypotension & $1(3.3 \%)$ & $2(6.7 \%)$ & $3(10.0 \%)$ & 0.49 \\
\hline Bradycardia & $0(0.0 \%)$ & $1(3.3 \%)$ & $2(6.7 \%)$ & 0.32 \\
\hline Respiratory depression & $0(0.0 \%)$ & $1(3.3 \%)$ & $2(6.7 \%)$ & 0.37 \\
\hline
\end{tabular}

VAS score Data expressed as median and range $p$ was calculated using Kruskal-Waills test ${ }^{*}$ denotes high statistical significance $(p<0.001) *$ denotes statistical significance $(p<0.05)$. Data expressed as mean and standard deviation (Mean $\pm \mathrm{SD})$, ANOVA $(\mathrm{F})$ test used ${ }^{*}$ denotes statistical significance $(p<0.05) \cdot p_{2}$ comparison between Group A and Group M. Post operative complications Data expressed as number (\%) Chisquare test used, $p$ is significant $p<0.05$.

Table 3. Post-operative Ramsay sedation score.

\begin{tabular}{ccccc}
\hline & $\begin{array}{c}\text { Group C } \\
\mathbf{N}=\mathbf{2 7}\end{array}$ & $\begin{array}{c}\text { Group A } \\
\mathbf{N}=\mathbf{2 8}\end{array}$ & $\begin{array}{c}\text { Group M } \\
\mathbf{N}=\mathbf{2 8}\end{array}$ & $p$ value \\
\hline Time of PACU admission & $4.5(1-6)$ & $4(1-5)$ & $4(1-5)$ & $0.046^{\star}$ \\
At one hour & $4(1-5)$ & $3(1-4)$ & $3(1-4)$ & $0.021^{\star}$ \\
At 2 hours & $3.5(1-5)$ & $2(1-3)$ & $2(1-3)$ & $0.006^{*}$ \\
At 3hours & $2(0-3)$ & $2(0-3)$ & $2(1-3)$ & 0.091 \\
At 6 hours & $1(1-1)$ & $1(1-1)$ & $1(1-2)$ & 0.46 \\
At 12 hours & $1(1-1)$ & $1(1-1)$ & $1(1-1)$ & 0.62 \\
At 24 hours & $1(1-1)$ & $1(1-1)$ & $1(1-1)$ & 0.62
\end{tabular}

Data expressed as median and interquartile range (IQR), ${ }^{*}$ denotes statistical significance $(p<0.05)$.

sedation score between groups after two hours post-operatively (Table 3).

\section{Discussion}

Regional blocks can effectively control post mastectomy pain. Local anesthetic with adjuvants can show better results in controlling post-operative pain [5]. In 
our study, 90 patients were enrolled and divided into 3 groups according to the local anaesthetic adjuvants used.

We found that patients received magnesium sulphate or adenosine as an adjuvant to the local anaesthetic had longer duration of the block compared to the bupivacaine only group with less use of post-operative analgesia. The same groups with adjuvants showed better early post-operative pain control and more sedative effect than the bupivacaine only group. Intra-operative heart rate and mean arterial blood pressure were lower in patients received adenosine and magnesium sulphate. Magnesium sulphate showed an advantage over adenosine as an adjuvant to the local anaesthetic in PECS block regarding the duration of the block and the total amount of morphine used.

Many authors recommended the use of different local nerve block modalities to control pain in patients having breast surgery. Kaya et al. studies the analgesic effects of post-operative interscalene block in patients undergoing modified radical mastectomy [19]. The authors found that the use of their technique improved post-operative pain and decreased the use of morphine consumption [19]. However, the authors concluded that the optimal method to control such pain has not been defined. Our study agrees with Kaya et al. findings regarding post-operative pain control and post-operative morphine requirements. The advantages of our study over Kaya et al. study are: 1) the block is performed pre-operatively ultrasound guided, 2) the never block technique (PECS block) is known to have little side effects compared to intrescaline brachial plexus block, and 3) the adjuvants drugs are used with bupivacaine to augment its action. Kaya et al. criticized their study and questioned their technique to be a good alternative to other regional blocks. Our technique has been proven to be an effective technique for this group of patients.

Bouzinac A et al. published a case report of bilateral PECS I and serratus plane blocks for a patient undergoing bilateral breast surgery [20]. The authors mentioned that the patient did not require any post-operative morphine and the authors recommended further studies to evaluate PECS I block and PECS II for unilateral breast surgery [20]. In the present study we evaluated the use of the recommended technique by Bouzinac A et al. Moreover, we compared different adjuvants to the local anaesthetic to achieve a maximum effectiveness. Bouzinac A et al. recommended the use of PECS I and II as a sole anaesthetic technique. In our study we showed their role in post-operative pain control and not a sole anaesthetic technique. Further studies should follow to investigate PECS block as a sole anaesthetic technique for breast surgery.

Bashandy GM et al. did a randomized control trial to investigate the analgesic effect of PECS I and II in patients undergoing breast cancer surgery [21]. The authors used local anaesthetic for PECS block without adding adjuvants such as adenosine and magnesium sulphate and found that their technique reduced the overall analgesic requirements [21]. In the present study we used adjuvants (adenosine and magnesium sulphate) to the local anaesthetic. The adjuvants 
augmented the analgesic effects of the local anaesthetic with longer duration of action. In our study the longer effect of the block can reduce the need of analgesics compared to the use of the local anaesthetics alone.

Magnesium sulphate is commonly used as an adjuvant to local anaesthetics. Lee AR et al. investigated the use of magnesium sulphate added to bupivacaine in interscaline block [11]. The authors found that adding magnesium sulphate prolonged the block and reduced post-operative pain [11]. The results of Lee AR et al. agree with our results, which showed the advantage of magnesium sulphate in pain control over the other additives.

Al-Refaey et al. did a blinded randomized controlled trail to show the effect of adding magnesium sulphate to bupivacaine in transversus abdominis plane block [22]. Gunduz A et al. did another study to investigate the use of the same mixture for axillary plexus block [12]. The results of both studies agree with ours regarding the increase in the block duration and decrease the dose of analgesics consumed.

Culebras X et al. studied the use of clonidine mixed with bupivacaine for interscaline block [23]. The authors found that this mixture did not affect the analgesic effect of the local anaesthetic. The authors found that the injecting clonidine for the local block decreased the mean arterial blood pressure and heart rate [23]. Our study showed similar results regarding the effect of the additives on haemodynamics. It is clear if any additives to a local anaesthetic can be absorbed systemically and produces its systemic pharmacological effects as well as a local effect. From the present study we cannot prove the systemic effect of the adjuvants.

Sawynok J wrote an article about the role of adenosine receptors in pain [15]. The author cam to conclusion that adenosine can regulate nociception and has an effect on chronic neuropathic pain. The author added that this drug should be further investigated regarding its analgesic role [15]. In the present study we took this drug a step further according to Sawynok J's recommendations and investigated its analgesic effect when used with a local anaesthetic. Our results suggested that adenosine has a local analgesic effect by increasing the duration of PECS block when used with bupivacaine.

Adenosine has been investigated in some clinical trials in clinical anaesthesia. Gan TJ et al. wrote an article showing that the use of adenosine can reduce the amount of anaesthetics during general anaesthesia [24]. The authors did not explore the use of adenosine as an adjuvant in local nerve block. Some experimental studies showed a significant effect of using adenosine as a pain modulator in neuropathic pain in rats [13] [14]. Other studies showed the advantage of using adenosine in spinal block in rats with antinociception and sedative effects [14].

Vey few authors investigated the role of adenosine as an adjuvant to local anaesthetics. Mahmoud and Ammar used adenosine in brachial plexus block [25]. The authors found advantages of using adenosine regarding the duration of the block and the consumption of post-operative analgesics. The authors recom- 
mended more studies to evaluate adenosine role in local nerve blocks [25]. The present study agrees with Mahmoud and Ammar. However, we also compared the effect of another adjuvant namely magnesium sulphate and found that it has better effect than adenosine when added to the local anaesthetic.

Memis D et al. showed that magnesium sulphate had a sedative effect [26]. In the present study we found that patients who received magnesium sulphate were more sedated than the control group. The sedative effect being delayed after injection may be because of the delayed absorption from the local injection site. Adenosine group being more sedated than the control group may be due to its antinociception effect.

\section{Conclusion}

PECS block is an effective technique in reducing post-operative pain in patients undergoing modified radical mastectomy. Adjuvants to local anaesthetics such as magnesium sulphate or adenosine can increase the duration of the block and decrease the use of postoperative opioids. Magnesium sulphate has advantages over adenosine regarding longer duration of the block. Further studies should be carried out to investigate the possibility of using PECS with magnesium sulphate as sole anaesthetic technique for breast surgery.

\section{References}

[1] DeSantis, C., Ma, J., Bryan, L. and Jemal, A. (2014) Breast Cancer Statistics, 2013. CA: A Cancer Journal for Clinicians, 64, 52-62. https://doi.org/10.3322/caac.21203

[2] Hirko, K.A., Soliman, A.S., Hablas, A., Seifeldin, I.A., Ramadan, M., Banerjee, M., et al. (2013) Trends in Breast Cancer Incidence Rates by Age and Stage at Diagnosis in Gharbiah, Egypt, over 10 Years (1999-2008). Journal of Cancer Epidemiology, 2013, Article ID: 916394. https://doi.org/10.1155/2013/916394

[3] Mohamed, S.A., Adbel-Ghaffar, H.S., Kamal, S.M., Fares, K.M. and Hamza, H.M. (2016) Effect of Topical Morphine on Acute and Chronic Postmastectomy Pain: What Is the Optimum Dose? Regional Anesthesia and Pain Medicine 41, 704-710. https://doi.org/10.1097/AAP.0000000000000496

[4] Fahy, A.S., Jakub, J.W., Dy, B.M., Eldin Harmsen, N.S., Sviggum, H. and Boughey, J.C. (2014) Paravertebral Blocks in patients Undergoing Mastectomy with or without Immediate Reconstruction Provides Improved Pain Control and Decreased Postoperative Nausea and Vomiting. Annals of Surgical Oncology, 21, 3284-3289. https://doi.org/10.1245/s10434-014-3923-Z

[5] Patarica-Huber, E., Boskov, N. and Pjevic, M. (2011) Multimodal Approach to Therapy-Related Neuropathic Pain in Breast Cancer. Journal of BUON, 16, 40-45.

[6] Gärtner, M., Kroman, N., Callesen, T. and Kehlet, H. (2010) Multimodal Prevention of Pain, Nausea and Vomiting after Breast Cancer Surgery. Minerva Anestesiologica, 76, 805-813.

[7] Kang, J.E., Park, S.K., Song, I.K., Lee, J.H., Kim, J.T. and Kim, H.S. (2015) Comparison of the Efficacy and Safety of Different Doses of Propacetamol for Postoperative Pain Control after Breast Surgery. Pain Management Nursing, 16, 367-371. https://doi.org/10.1016/j.pmn.2014.08.016

[8] Cajanus, K., Kaunisto, M., Tallgren, M., Jokela, R. and Kalso, E. (2014) How Much 
Oxycodone Is Needed for Adequate Analgesia after Breast Cancer Surgery: Effect of the OPRM1 118A>G Polymorphism. Journal of Pain, 15, 1248-1256.

https://doi.org/10.1016/j.jpain.2014.09.002

[9] Blanco, R., Fajardo, M. and Parras Maldonado, T. (2012) Ultrasound Description of Pecs II (Modified Pecs I): A Novel Approach to Breast Surgery. Revista Española de Anestesiología y Reanimación, 59, 470-475. https://doi.org/10.1016/j.redar.2012.07.003

[10] Blanco, R. (2011) The "Pecs Block": A Novel Technique for Providing Analgesia After Breast Surgery. Anaesthesia, 66, 847-848. https://doi.org/10.1111/j.1365-2044.2011.06838.x

[11] Lee, A., Yi, H., Chung, I., Ko, J., Ahn, H., Gwak, M., et al. (2012) Magnesium Added to Bupivacaine Prolongs the Duration of Analgesia after Interscalene Nerve Block. Canadian Journal of Anesthesia, 59, 21-27. https://doi.org/10.1007/s12630-011-9604-5

[12] Gunduz, A., Bilir, A. and Gulec, S. (2006) Magnesium Added to Prilocaine Prolongs the Duration of Axillary Plexus Block. Regional Anesthesia and Pain Medicine, 31, 233-236. https://doi.org/10.1097/00115550-200605000-00010

[13] Sjolund, K., Sollevi, A., Segerdahl, M. and Lundeberg, T. (1977) Intrathecal Adenosine Analog Administration Reduces Substance P in Cerebrospinal Fluid along with Behavioral Effects That Suggest Antinociception in Rats. Anesthesia \& Analgesia, 85, 627-632. https://doi.org/10.1213/00000539-199709000-00025

[14] Gomes, J., Li, X., Pan, H. and Eisenach, J. (1999) Intrathecal Adenosine Interacts with a Spinal Noradrenergic System to Produce Antinociception in Nerve-Injured Rats. Anesthesiology, 91, 1072-1079. https://doi.org/10.1097/00000542-199910000-00028

[15] Sawynok, J. (2016) Adenosine Receptor Targets for Pain. Neuroscience, 338, 1-18. https://doi.org/10.1016/j.neuroscience.2015.10.031

[16] McComack, H., Horne, D. and Sheather, S. (1998) Clinical Applications of Visual Analogue Scales: A Critical Review. Psychological Medicine, 18, 1007-1019. https://doi.org/10.1017/S0033291700009934

[17] Ammar, A.S., Mahmoud, K.M. and Kasemy, Z.A. (2017) Comparison between Adenosine and Magnesium Sulphate as Adjuvants for Transversus Abdominis Plane Block: A Prospective Randomized Controlled Trial. Minerva Anestesiologica, 84, 304-310.

[18] Fifer, S., O'Connor, A. and Fisher, M. (1999) A Prospective Randomised Pilot Study of Sedation Regimens in a General ICU Population: A Reality-Based Medicine Study. Critical Care, 3, 79-83. https://doi.org/10.1186/cc344

[19] Kaya, M., Oğuz, G., Senel, G. and Kadıoğulları, N. (2013) Postoperative Analgesia after Modified Radical Mastectomy: The Efficacy of Interscalene Brachial Plexus Block. Journal of Anesthesia, 27, 862-867.

https://doi.org/10.1007/s00540-013-1647-z

[20] Bouzinac, A., Brenier, G., Dao, M. and Delbos, A. (2015) Bilateral Association of Pecs I Block and Serratus Plane Block for Postoperative Analgesia after Double Modified Radical Mastectomy. Minerva Anestesiologica, 81, 589-590.

[21] Bashandy, G. and Abbas, D. (2015) Pectoral Nerves I and II Blocks in Multimodal Analgesia for Breast Cancer Surgery: A Randomized Clinical Trial. Regional Anesthesia and Pain Medicine, 40, 68-74. https://doi.org/10.1097/AAP.0000000000000163

[22] Al-Refaey, K., Usama, E. and Al-Hefnawey, E. (2016) Adding Magnesium Sulfate to 
Bupivacaine in Transversus Abdominis Plane Block for Laparoscopic Cholecystectomy: A Single Blinded Randomized Controlled Trial. Saudi Journal of Anaesthesia, 10, 187-191. https://doi.org/10.4103/1658-354X.168821

[23] Culebras, X., Van Gessel, E., Hoffmeyer, P. and Gamulin, Z. (2001) Clonidine Combined with a Long Acting Local Anesthetic Does Not Prolong Postoperative Analgesia after Brachial Plexus Block but Does Induce Hemodynamic Changes. Anesthesia \& Analgesia, 92, 199-204.

https://doi.org/10.1097/00000539-200101000-00038

[24] Gan, T. and Habib, A. (2007) Adenosine as a Non-Opioid Analgesic in the Perioperative Setting. Anesthesia \& Analgesia, 105, 487-494. https://doi.org/10.1213/01.ane.0000267260.00384.d9

[25] Mahmoud, K. and Ammar, A. (2011) Ultrasound-Guided Continuous Infraclavicular Brachial Plexus Block Using Bupivacaine Alone or Combined with Adenosine for Pain Control in Upper Limb Surgery. Saudi Journal of Anaesthesia, 5, 132-137. https://doi.org/10.4103/1658-354X.82779

[26] Memis, D., Turan, A., Karamanlioglu, B., Oguzhan, N. and Pamukcu, Z. (2003) Comparison of Sufentanil with Sufentanil plus Magnesium Sulphate for Sedation in the Intensive Care Unit Using Bispectral Index. Critical Care, 7, R123-R128. https://doi.org/10.1186/cc2365 